\title{
Influence of climate variability on large rivers runoff
}

\author{
B. Nurtaev \\ Solterra Science, Kapfenberger Straße 17, 50226 Frechen, Germany \\ Correspondence to: B. Nurtaev (nurtaev@gmx.net)
}

\begin{abstract}
In accordance with IPCC Report the influence of climate change on the water cycle will increase hydrologic variability by means of changing of precipitation patterns, melting of ice and change of runoff. Precipitation has increased in high northern latitudes and decreased in southern latitudes. This study presents an analysis of river runoffs trends in different climatic zones of the world in condition of climate change.
\end{abstract}

\section{Introduction}

The main driving force of climate and in hydrologic cycle is the solar radiation. Earth gets all its energy from the Sun and it is the Sun's energy that keeps Earth warm. $99.97 \%$ of the energy that enters our climate system comes from the Sun, geothermal energy is $0.025 \%$. The current world energy consumption is equivalent to just $0.007 \%$ of the incident solar energy Taylor (2005). The amount of energy Earth receives is not always the same. Changes in the Sun and changes in Earth's orbit affect the amount of energy that reaches the Earth. Over the period 1850 to 1996 was observed steady increase of sunspots on the Sun. During this period also was observed an increase in temperature in the Northern Hemisphere.

At the same time over the last century we observe different trends in climate and water systems: constant air temperature rise and decrease or increase of river discharges. The hydrological cycle is a closed system, because there are no external inputs or outputs of water to or from the system. The same water has been continually circulating since the beginnings of life on Earth. Amount of water circulated in atmosphere and hydrosphere depends eventually on capacity and a finite extension of the atmosphere due to warming as well as from the Earth gravitational force for the vapour water molecule in atmosphere.

\section{Methodology}

The source of virtually all the energy in the climate system of the Earth is radiation from the Sun. The $F 10.7 \mathrm{~cm}$ index is a standard characteristic of solar activity using in research concerning the solar influence on Earth's climate. Compar- ison of F10.7 cm index with Wolf's Numbers has detected correlation between these both parameters $r=0.99$.

Taking into account the solar $\mathrm{F} 10.7 \mathrm{~cm}$ record extends back to 1947 and sunspots record since 1750 and the postulate, that the main driver of hydrological cycle is primarily solar radiation as illustrated in Fig. 1, we examined relationships between evolution of the long-term mean river runoffs, air temperature and sunspots for one solar cycle:

$$
\begin{aligned}
& W=\frac{1}{n} \sum_{i=0}^{n} W i \\
& Q=\frac{1}{n} \sum_{i=0}^{n} Q i \\
& T=\frac{1}{n} \sum_{i=0}^{n} T i
\end{aligned}
$$

where $W$ - averaged sunspot number for one solar cycle with length from $n=9$ years up to 14 years; $Q$ - averaged amount of water discharge appropriate for one solar cycle with length from $n=9$ years up to 14 years, $\mathrm{km}^{3} ; T$ - averaged air temperature for one solar cycle ${ }^{\circ} \mathrm{C}$.

This averaging allows avoiding a seasonal and a temporal variability of river discharge and air temperature. Averaging over 9-14 years as a rule in case of water use or dams filling gives a smoothed effect. After filling of reservoirs or dams, river runoff tends to natural behavior as in the Baikal Lake. Increasing of temperature in studied regions changes from $+0.2 \ldots,+0.7$ in the Tibetan Plateau up to $+1.4^{\circ} \mathrm{C}$ in other river basins. 


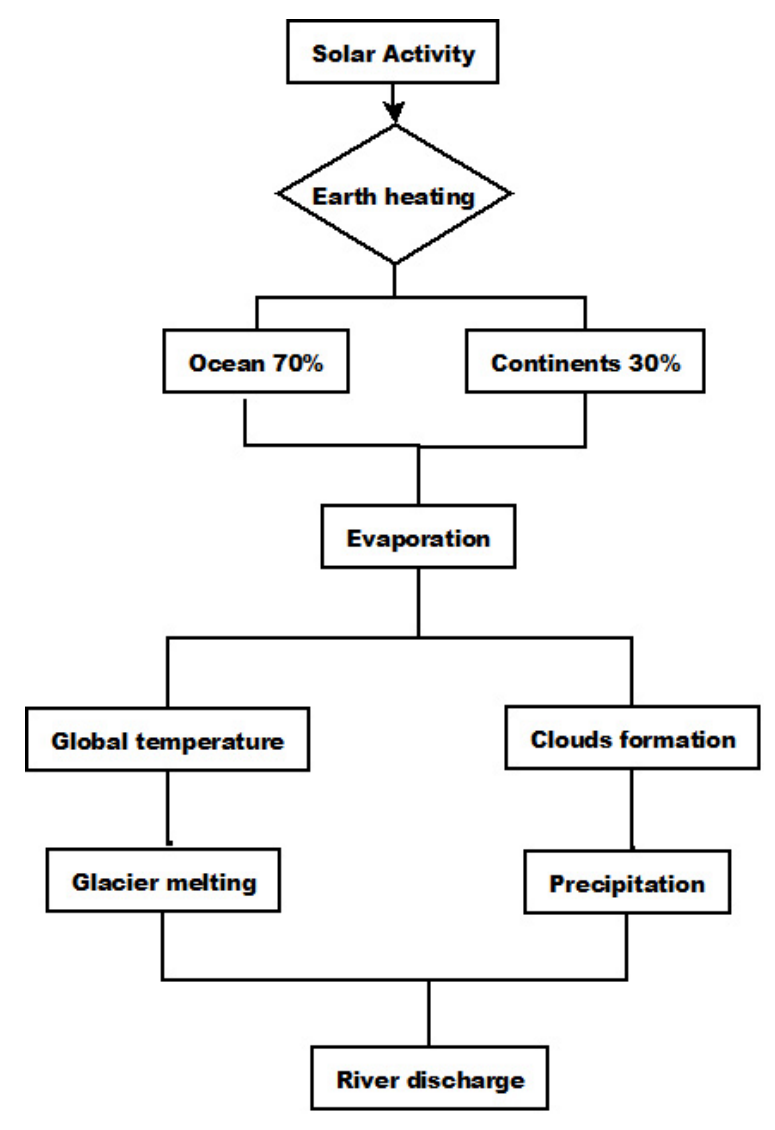

Figure 1. Scheme of river runoff formation.

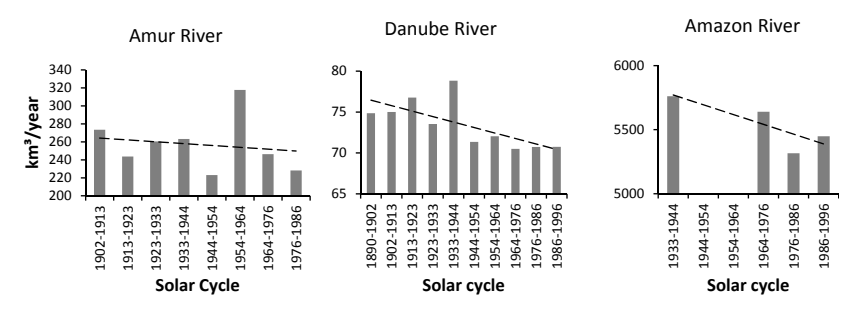

Figure 2. Rivers discharge flowing in sub-latitudinal direction and trends.

\section{Rivers discharge trends flowing in sub-latitudinal direction}

1. The Amazon River discharge data of GRDS covers the period from 1933-1996 with gaps in 1944-1964. Therefore there were considered 4 solar cycles or 44 years. Calculation show a statistically significant decreasing trend in the river flow(about $300 \mathrm{~km}^{3}$ over the studied period). Wind patterns in this region are Southeast Trades, which pick up moisture from the Atlantic Ocean and generate precipitation in the Amazon River Basin. The temperature increase in the basin leads to increase of evaporation and to decrease of runoff (Fig. 2).
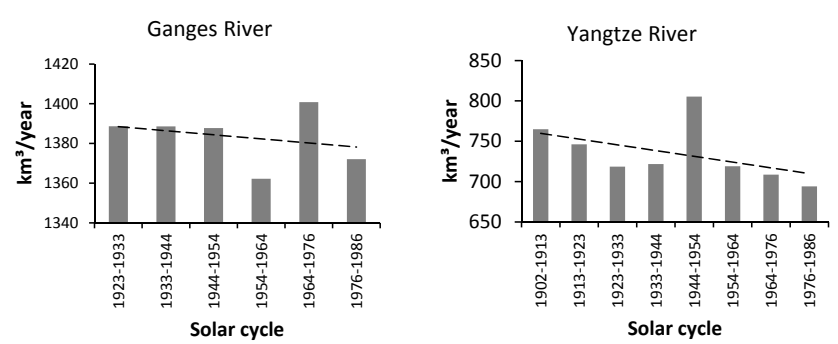

Figure 3. Ganges, Yangtze rivers discharge and trends.

2. The analysis of the long term average discharge of the Danube River is revealed that within Middle Section the discharge rates declined (station Nagymaros) (Fig. 2). The river flow more susceptible after the Iron Gate Dam to water formations factors of the lower reaches tributaries of the Danube River. Temperature rise in the river basin reached $+1.0 \ldots+1.5^{\circ} \mathrm{C}$ and precipitation rise just 30-60 mm over the period 1890-1996.

3. The Amur River runoff decreased in average on $50 \mathrm{~km}^{3}$ year $^{-1}$ over the period 1902-1996, temperature rise in the basin reach about $+1.0 \ldots+1.4^{\circ} \mathrm{C}$ in the same period. Increase of water in the river, during 19541964 is connected with phenomena of global dimming period 1960-1990.

\section{The Ganges and the Yangtze rivers runoff trends}

The Himalayas are a major barrier for the natural flow of the southwest monsoon (5000 $\mathrm{m}$ a.s.1.). Temperature rise of weather stations Mumbai, Nagpur, Madras, Bangalore and Hyderabad corresponds to more active Sun and reach $0.4-0.6^{\circ} \mathrm{C}$ over the period $1890-1996$. Rivers Ganges and Yangtze are perennial as they get water from the rainfall as well as the melting of ice. The contribution of snow and glacier- melt runoff to Himalayan Rivers is significant. The steady temperature increase reduces the Yangtze (station Hankou) and Ganges rivers runoff. The melting glaciers less and less feeding the Ganges River and the Yangtze River. In accordance with scientific reports the total area of glaciers had decreased to 1051 from $1283 \mathrm{~km}^{2}$ in area of glaciers had decreased to $1051 \mathrm{~km}^{2}$ from $1283 \mathrm{~km}^{2}$ in 1971 in the source area of the Yangtze River. Nearly 1 billion cubic meters of glaciers were melting yearly. This corresponds with long term decrease of the Yangtze River (Fig. 3).

\section{Rivers with positive runoff trends}

The Mississippi River runoff increased steady with diminishing of averaged discharge in period 1933-1944 due to construction of locks and dams. After filling of reservoirs-water flow was normalized. The second period of the runoff decrease connected with global dimming (Fig. 4). The Rhine 

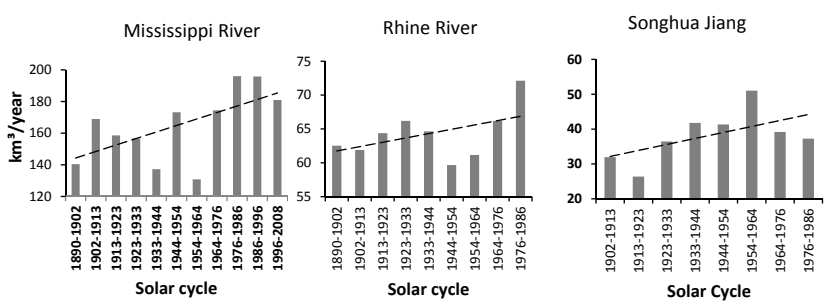

Figure 4. Rivers with positive discharge trends.

River runoff points out steady increase with excluding periods 1933-1944 and 1954-1964 (Fig. 4). Temperature increase in upper reach of the river varies from $+0.6 \ldots 1.5^{\circ} \mathrm{C}$. The Songhua Jiang River indicates stable increase of runoff. The temperature increase in the river basin $1.0^{\circ} \mathrm{C}$.

\section{Solar activity and air temperature trends}

In all studied river basins were observed increasing of air temperature. The same method described in Sect. 2 was applied for finding the connection between the solar activity and air temperature of weather stations in the same period of time in studied watersheds. Temperature trends in the Yangtze River watershed in dependence on solar activity in following weather stations:

Kunming : $T=-0.02 \mathrm{~W}+17,02, r=0.87$

Wuhan : $T=-0.02 \mathrm{~W}+18.09, r=0.83$

Yichang: $T=-0,02 \mathrm{~W}+18.17, r=0.77$

Temperature trends in Hindustan Peninsula:

Hyderabad: $T=0.01 \mathrm{~W}+25,73, r=0.75$

Bangalore : $T=0.02 \mathrm{~W}+22,99, r=0.88$

Temperature trend in the Songhua Jiang River watershed:

Harbin : $T=0.02 \mathrm{~W}+2,53, r=0.83$

Temperature trend in the Amur River watershed:

Blagoveshensk : $T=0.02 \mathrm{~W}+2.53, r=0.77$

Temperature trends in the Mississippi River watershed:

Minneapolis : $T=0.03 \mathrm{~W}+11.14, r=0.76$

St Cloud : $T=0.01 \mathrm{~W}+5.3, r=0.77$

Temperature trends in Danube River watershed:

Wien : $T=0.02 \mathrm{~W}+8.11, r=0.89$

Budapest : $T=0.02 \mathrm{~W}+8.85, r=0.88$

Temperature trends in the Rhine River watershed over the period 1784-1996:

Geneva $: T=0.02 \mathrm{~W}+8.64, r=0.87$

Karlsruhe $: T=0.03 \mathrm{~W}+8.4, r=0.87$
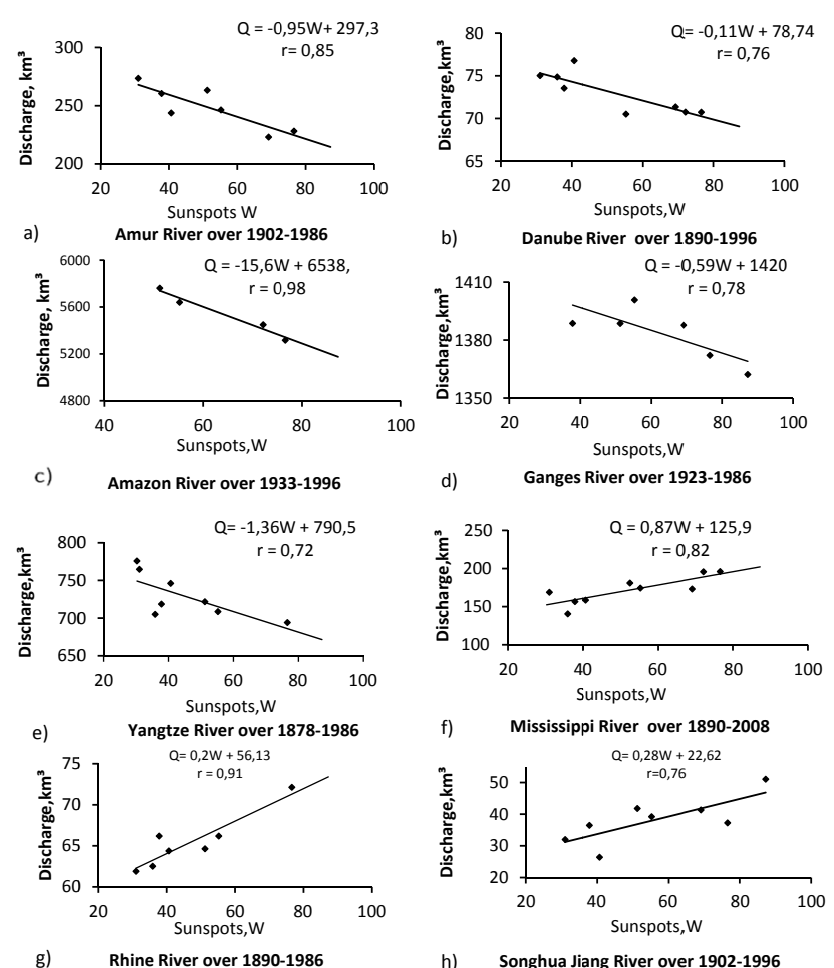

g)

h) Songhua Jiang River over 1902-1996

Figure 5. Relationships of rivers discharge in dependence on solar activity over a period of many years. Where $Q$ - river discharge in $\mathrm{km}^{3}, W$ - sunspots number, $r$ - coefficient of correlation.

where $T$ - air temperature in ${ }^{\circ} \mathrm{C}, W$ - sunspots number, $r$ coefficient of correlation.

\section{Long term trends of river runoffs in dependence from solar activity}

The river runoff comes from total watershed area and is concentrated into a single channel that acts like an integrator. River flow provide a single-point measurement; giving both large-scale averaging in catchments and amplification (Hoyt and Schatten, 1997). River discharge measurement over the long term period can be also considered as a cumulative effect of local weather parameters such as temperature, wind, rainfall, snow, glaciers melting and ocean currents, as well as interaction among these. The cause of all of the above variables is the solar radiation and indicator of the sun activity are sunspots. Empirical relationships between solar activity phases and river discharge presented in Fig. 5. In charts Mississippi, Rhine and Yangtze rivers withdraw 19 solar cycle (1954-1964). In this period was observed global dimming. In present time there is no calculation method of influence of global dimming on river discharge. 


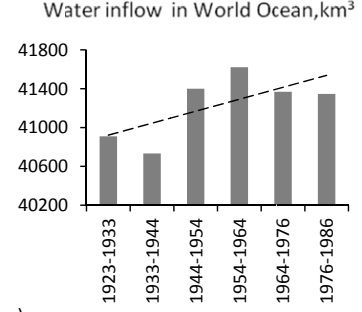

a)

Figure 6. Water inflow trend into the World Ocean (a) and relationship of the inflow from sunspots (b).

\section{Dynamics of water inflow to World Ocean}

Analysis of dynamics of water inflow into the World Ocean (1921-1985) shows long term increase of rivers discharge in ocean, Shiklomanov (1999) (Fig. 6a). Global warming and climate change both refer to the observed century-scale rise in the average temperature of the Earth's climate system lead, in general, to intensification of atmosphere circulation and of the water cycle. Calculation of averaged global inflow and solar activity show that runoff to the ocean increase with high solar radiation. Correlation coefficient -0.82 (Fig. 6b).

\section{Conclusions}

An activation of atmospheric circulation due to temperature rise causes the water cycle more intense. In this way orography plays a crucial role in a change in atmospheric conditions caused by a change in elevation, primarily due to mountains. The mountain ranges intercept a mass transfer of evaporated water. The climate on the leeward side of a mountain differs from that on the windward side mostly in the amount of rainfall. In accordance with NGDC forecasting the solar cycles 24 and 25 will be very weak. Averaged sunspot numbers $W=35$ for the solar cycle 24 and for the solar cycle 25 less than $W=35$, NGDC (2009). This actually will lead to a decrease of the temperature on $1-1,5^{\circ} \mathrm{C}$ in the both averaged solar cycles. Rivers discharge will be change in dependence from their geographical location. In catchments area of rivers Yangtze, Amur, Amazon, Ganges and Danube will be more floods and in watersheds of rivers Rhine, Songhua Jiang and Mississippi will be more droughts during 24 and 25 solar cycles - up to 2030. Averaged river runoff projection in future for these cycles can be found in Figs. 5 and 6 with $W=35$ and $W<35$ respectively. Global water inflow into the World Ocean will be decrease due to more accumulation of water in mountains glaciers.
Acknowledgements. The source of data: Global Runoff Data Centre, Koblenz, Germany, NGDC Surface Temperature Dat.

\section{References}

Douglas, V., Hoyt, K., and Schatten, H.: The role of the sun in climate change, Oxford University Press, Oxford UK, 279 pp., 1997.

NGDC - NOAA National Geophysical Data Center: http://www.ngdc.noaa.gov/stp/space-weather/ solar-data/solar-indices/sunspot-numbers/predicted/table_ international-sunspot-numbers_monthly-predicted.txt (last access: March 2015), 2009.

Shiklomanov, A.: International Hydrological Programme, available at: http://webworld.unesco.org/water/ihp/db/shiklomanov/part\% 272/Tb_10.html (last access: March 2015), 1999.

Taylor, F. W.: Elementary Climate Physics, Oxford University Press, Oxford, p. 232, 2005. 